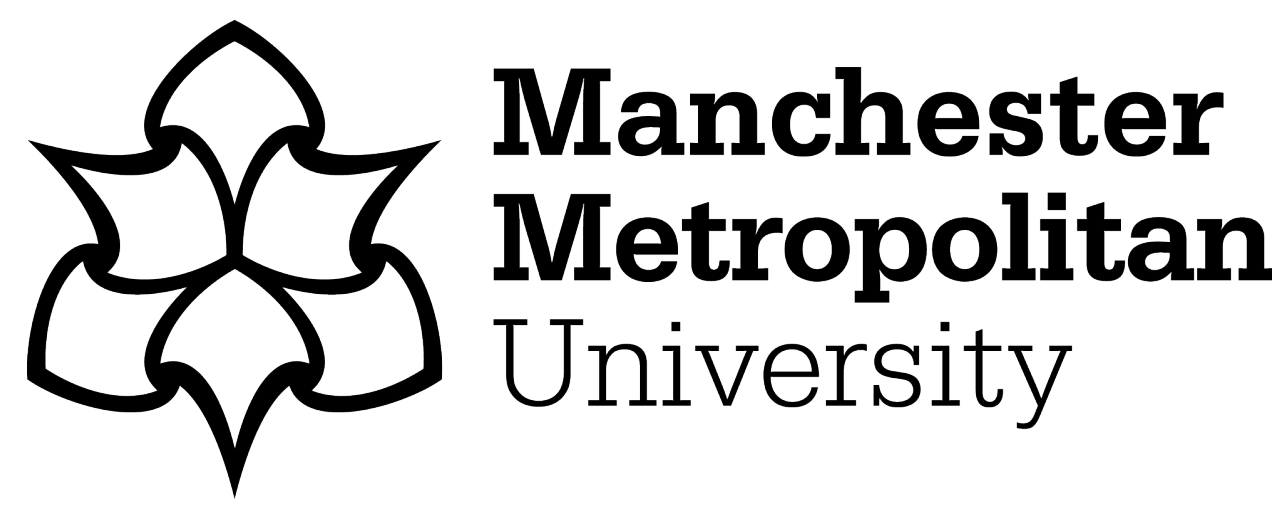

McNicol, SL ORCID logoORCID: https://orcid.org/0000-0001-8196-6680 (2018) Telling migrant women's life stories as comics. Journal of Graphic Novels and Comics, 9 (4). pp. 279-292. ISSN 2150-4857

Downloaded from: https://e-space.mmu.ac.uk/620087/

Version: Accepted Version

Publisher: Taylor \& Francis (Routledge)

DOI: https://doi.org/10.1080/21504857.2018.1449125

Please cite the published version 


\section{Telling migrant women's life stories as comics}

\section{Introduction: comics and life writing}

This article considers the role of comics in the construction and interpretation of migration stories, in particular migrant women's life stories. Drawing on examples from a community-based project involving a group of women born in Bangladesh but now living in the UK, it outlines how even as novice comics creators, they were able to employ features of comics to communicate their life stories in highly effective ways.

Many of the most well-known, and well-loved, graphic novels are at least partially autobiographical, for example, Maus (Spiegelman 2003), Fun Home (Bechdel 2006) and Blankets (Thompson 2003). In her 2008 monograph, Lisa El Refaie identified 85 books that she felt demonstrated the broad spectrum of autobiographical comics then available in North America and Western Europe. Why is life writing so prevalent as a theme of recent graphic novels and comics? One reason may be that a hybrid text-image format offers an effective way to deal with the uncertainty and disorder inherent in life story. As Hillary Chute argues, 'images in comics appear in fragments, just as they do in actual recollection' $(2010,4)$. She claims that, through the use of space to interlace or overlay different temporalities, comics can challenge conventional notions of progression and sequencing. Furthermore, a common feature of comics is the use of 'doubled narration', for example, showing pictures from a child's perspective, but with adult narration, a technique highly suited to the telling of life stories.

Comics may also allow for a wider variety of forms of autobiography than those traditionally encountered. As Michael Chaney argues, 'When the 'l' of autobiography is explicitly stylized as a kind of cartoon, the result is a brazen departure from the 'seemingly substantial' effects of realism that traditional autobiographies presume' $(2011,7)$. This may, for example, allow for the exploration of intersections between individual and communal histories, or between factual, fictional, metaphorical or counter-factual elements. Rocío Davis has argued that, 'autobiographical comics in particular are a distinctive and rewarding domain for exploration from a critical, cultural and gender perspective' $(2005,267)$ and an effective way 'to literally represent memory, dreams, possibilities, and engage the idiosyncrasies of the present' $(2005,268)$. Furthermore, it has been argued that women's comics in particular can, 'make visible fragments of traumatic experience that formerly have been neglected, repressed, or censored' (Ulanowicz 2011). 
Female comics creators have long been highly active and influential in the field variously termed autobiographical comics, graphic memoir, autography or autobiographix. For example, the Wimmen's Comix Collective, formed as part of the underground comix movement of 1970s, created comics that were often subversive, concerned with feminist self-actualization and sexually explicit. Moreover, the closely-related format of zines (and e-zines) have long offered women and girls safe, supportive spaces for self-expression and opportunities for collective creative production. More recently, there has been growing interest in women's exploitation of graphic narrative to depict, 'what is often placed outside of public discourse' (Chute 2010,5), or 'the drama of the domestic and the everyday'i. Common foci include illness, travel, childhood, exile and personal or family crises. Creators also frequently comment on the process of comics creation itself.

Considering the role of comics in the telling of migration stories in particular, it has been argued that comic books 'have always been attuned to the experiences of immigrant Others' (Davis-McElligatt $2010,137)$. Comics have long played a crucial role in representing and constructing immigrant subjects and the immigrant experience. There are several widely known graphic novels that address issues of migration, including Chris Ware's (2001) Jimmy Corrigan: The Smartest Kid on Earth and Shaun Tan's (2007) The Arrival. However, as in other formats, male narratives can dominate. Tan's wordless graphic novel, The Arrival, is often said to depict a universal story of migration, telling 'not an immigrant's story, but the immigrant's story' (Yang 2007). However, it is explicitly a story of a man's migration as he leaves his wife and daughter behind to make a better life in a new land. At the end of his struggles, the man reunites his family who appear to settle seamlessly into their new life without experiencing any of the hardships he has endured.

\section{Life writing traditions}

Historically, Western forms of life writing have largely followed a White, male, upper- or middle-class model based on the notion of individualism and claims to factual accuracy. However, life stories may also be told or written in ways that are very different ways from familiar Western concepts.

Alternative models of life narrative exist in which the notion of self is more fluid, fragmented and multifarious, allowing 'the authors and the readers to explore links between multiple languages and selves' (Pavlenko 2001, 217). It is common for autobiographers who chose such approaches to describe a 'discontinuous identity': who they were in the past is not necessarily who they are now. In this type of life writing, it is often impossible to draw strict boundaries between factual and fictional accounts as memory is always incomplete and retelling involves 'selection and artful construction' (El Refaie 2008, 12). Anneleen Masschelein (2008) labels such works 'autofiction'. Indeed, Timothy 
Dow Adams describes autobiography as the 'la frontera: borderland between fiction and nonfiction' $(2000,20)$, where, as Lisa El Refaie argues, 'imagination may sometimes provide a more adequate expression of subjective truths than can be achieved by sticking to literal facts' $(2008,16)$. This relates to the idea expressed by Michael Chaney that autobiographies may not be 'verifiably true', but they are generally expected to be 'emotionally truthful to the way they perceive, remember, and make sense of' an author's life $(2011,3)$. This notion of an emotional truth, which challenges 'the assumption that honesty lies in personal revelation' (Gilmore 2001, 24), might be expressed through techniques such as fictionalising, mythologizing and the use of pseudonyms.

This article will contribute to these debates around various modes of life narrative, with a particular focus on migration narratives. In this context, alternative forms of autobiography such as those mentioned above may be particularly relevant because, as Urszula Chowaniec (2015) argues, 'Exile shows that identity is not a stable, once given and persistent quality'. However, here too, male stories and approaches have traditionally dominated. As Aneta Pavlenko argues, 'immigrant women's stories were continuously ignored by the literary establishment' $(2001,220)$. For example, Sandra Courtman (2012) comments on, '...the invisibility of women of the Windrush generation in the memorial timeline' which means that 'this arrival story has largely been memorialised as masculine'. While, conventionally, the primary agenda of (largely male) immigrant autobiographers has been to adopt the format of a 'heroic quest' illustrating success and avoiding anxieties, pains and losses, it has been suggested that female migrant life writing may explore different themes. For example, Aneta Pavlenko (2001) sees the connection between language learning and gender as a dominant theme.

Urszula Chowaniec (2015) writes of important shifts in the cultural understanding of migration (or displacement) experiences that have emerged from female writers' scrutiny of this topic. There is a focus on gender-related issues, represented by a shift 'from the universalized experience of emigration or migration to the gendered experience of displacement, where the feminine aspect is especially emphasized'. Alongside this is 'the shift from the notion of a stable identity to a variable identity...that changes depending on place, cultural neighbourhood and-which is probably the most important-language'.

\section{The structure of comics}

As indicated above, there are a number of features of the comics format that are important to the telling of life stories: the dual text-image format; the notion of gaps; and the interplay between space and time. These are described in turn below. 
Comics are frequently said to be, 'more than the sum of their parts'; they are not simply an illustrated narrative, but 'operate on a system of co-presence' (Beaty 2011, 108). As a hybrid wordimage format, comics are said to have 'dual narrative tracks' (Chute 2008, 452) which require the reader to develop a number of strategies to make sense of the various possibilities presented. The reader must negotiate two systems of codes which sometimes function independently, but at other times interact. Although image and text need to work together in a comic, this does not necessarily mean that the two components always convey the same message. For example, the picture may show a character's outward behaviour, while a thought bubble conveys their true feelings. To fully comprehend a comic, the reader needs to take account of both. Furthermore, even if the image and text appear to be telling the same story, they do not necessarily present events at the same time, in the same order, or from the same viewpoint. This means that comics need not have a single, clear message; on the contrary, they are often characterised by the presence of multiple messages. The process of deciphering these ambiguous messages can be less straightforward than it might first appear.

In addition, the textual element of comics can be particularly complex in migration narratives: words from other languages may be used and also the type(s) of English adopted may vary. 'New Englishes' (Jenkins 2006) occur in situations where English has been learnt as a second language, or is one of a multilingual selection of languages available, for example, Indian Englishes or Nigerian Englishes. Arguably, the 'pictorial language' of comics is more straightforward as a shared language is not required to interpret images. However, it is important to remember that certain images may be culturally specific and it is possible that images might be interpreted in different ways within different cultures. It is also noteworthy that comics is a medium which crosses many cultures, but in doing so, it can take distinct forms and characteristic styles, for example, Japanese manga and Chinese manhua; South and Central American fotonovelas (photo stories); and Filipino komiks that draw on traditional folklore as well as elements of mainstream American comics.

It is not just the words and images a creator choses to include which are important to the understanding of a comic however. Comics present a series of panels, or 'visual fragments' (Groensteen 2007), which might be thought of as echoing Salman Rushdie's (1982) notion of 'shards of memory'. He describes how the fragmentary nature of memories can make them particularly evocative. As a series of fragmented, static images, comics omit far more information than they include. Wolfgang Iser's (1989) notion of 'gaps', absences of connections that readers must fill in 
order to make sense of the text, becomes critical in understanding the act of reading a comic as, in this format, the 'gaps' take the particularly striking form of gutters between frames. Readers therefore need to 'read between the panels' (Brenner 2006, 125) in order to complete the narrative. It can be argued that what is omitted (left in the gutter) is just as significant as what is included within the panels and it is the reader's interpretation of these 'gaps' which allows them to make sense of the story.

Another relevant feature of comics is the freedom they give to the reader to add their own dimension of time. This flexibility in the presentation of time can be critical to the telling of a life story. One example of this is in the way in which multiple perspectives can be shown within the same frame, thus presenting the reader with images from past and present (and perhaps future) simultaneously. As Scott McCloud points out, a single image in a comic, does not necessarily represent a single moment in time. On the contrary, in comics, past and future are not simply 'memories' and 'possibilities', but are 'real and visible and all around us!' $(1994,104)$. The comics format allows the reader to constantly shift backwards and forwards through time as their eyes drift away from the 'now' panel to those preceding or succeeding. Hillary Chute describes the potential power this can have, especially in the narration of traumatic stories: 'Comics can express life stories, especially traumatic ones, powerfully because it makes literal the presence of the past by disrupting spatial and temporal conventions to overlay or palimpsest past and present' $(2011,109)$. Through such techniques, comics are able to play with, and disrupt, conventional representations of time. According to Lisa El Refaie comics are, 'well suited to the task of conveying subjective time, since many of its formal features follow patterns that reflect the way memory itself works' $(2010,281)$. Thus, in comics, meaning not only emerges by virtue of the logical sequence of panels, but also through associative links across a page or even a whole work. Furthermore, the composition of comics plays on the intimate links between our experience of time and of space that is so central to migration narratives.

\section{Comics creation as research}

This article considers comics as a site of construction and interpretation, rather than as a source of data to analyse or as a method to present research. 'Graphic Lives: telling Bangladeshi migrant women's stories through graphic narratives' was a project funded by the UK Heritage Lottery Fund (HLF) and run collaboratively by [name of university] and a local charity, [name of charity], which works with women from the British Bangladeshi community in the borough of Tameside in Greater Manchester. This project was felt to be important because, to date, the potential of comics to 
engage communities in research, especially those who may be more reluctant to participate via traditional research methods, has received relatively little attention.

In a previous research project involving some of the same research team, a day-long comics-making workshop had been facilitated by artist Jim Medway (Author 2017). Participants were supported in developing basic drawing skills before designing their own comics around themes such as political awareness and beliefs; division and disconnection in society; and imaginings for a better future. Although aspects of this workshop helped to inform the development of the Graphic Lives project, there were notable differences as it had involved working with a very different group of White, and largely male, trade union activists.

There are more similarities between Graphic Lives and the project described by Sofia Gameiro and colleagues (forthcoming) as this had also involved a group of Black and Minority Ethnic (BME) women. In this case, a workshop on 'metaphor-centred drawing' had enabled participants with differing English language proficiency and cultural backgrounds to express highly emotional, and often tabooed, experiences of infertility. The women's words and drawings were used to create a booklet with the support of an artist ${ }^{1}$.

Alongside these research projects, it is also worth noting the work of organisations such as Grassroots Comicsii that promotes the use of comics 'drawn by common people reflecting their understanding of the social world (and not by artists)' as 'a communication tool' as well as a 'medium for self-expression'.

In most these types of projects, however, the creation of comics took place over a relatively short period. A key difference in Graphic Lives was that we worked intensively with a group of women over a number of months. In addition, the objective was that the women themselves would create their own digital comics using tablet computers, so while they could include drawings, they also had the option to use photographs and digitally-created images in their comics.

\section{The Graphic Lives project}

Over a period of five months in spring and summer 2017, nine women from Hyde in Greater Manchester, UK explored their own life stories and the historical narratives of their communities through workshops on life history, cross-cultural storytelling and digital skills. For example, they learnt how to take and edit photographs using mini-tablet computers; they plotted their stories using pin boards and string; and they discussed extracts form oral history transcripts available in

\footnotetext{
${ }^{1}$ http://psych.cf.ac.uk/engagementimpact/thornsandflowers/docs/Thorns\%20and\%20Flowers.pdf
} 
local archives. The group also visited museums and galleries to engage with collections, in particular objects from South Asia. The majority of sessions were led by a facilitator from [name of university] and a learning support worker/interpreter from [name of charity]. Guest facilitators ran two of the sessions and museum/gallery staff supported the visits. Table 1 outlines the various sessions in the preparatory stage of the project.

[Table 1 here]

The idea behind this preparatory phase was that it would give the women some of the basic skills they needed to construct their own comics, but it also encouraged them to explore the aspects of their story, or the ways of telling their story, that they were most comfortable with and that felt most 'truthful' to them. Following these preparatory activities, the women then used mini-tablet computers and a simple online tool called Book Creatoriii to communicate their own multimedia story using photographs, drawings and text. The aim of this method of comics creation was to give the women themselves opportunities to construct and tell their own stories, in their own voice and in their own ways. So, whilst some produced drawings that they then scanned and added to their comic; others searched online for stock images; and yet others made copies of their own family photographs and digitally altered them to avoid individuals being easily recognisable. We chose to produce digital comics so the women were not put off by a lack of confidence in their drawing skills. In addition, a number were keen to improve their digital skills and this project offered them an opportunity to different types of digital tools then those they were used to. In producing their final comics, most of the women used a combination of these methods. It should be noted that, although Book Creator has recently added comics features such as panel layouts and speech bubbles, these were not available during the project and this determined the page layout options used by the women to some extent.

\section{Identities depicted through the comics}

The following section identifies some of the common themes that emerged from the women's comics as their explored their Bangladeshi identity; questioned aspects of their identity as a result of migration experiences; and attempted to forge a new identity in the UK. Although this may give the impression of a chronological sequence, it is important to point out that very few of the women actually chose to tell a chronological life story. Most challenged notions of progression and sequencing, moving backwards and forward through time and place, between the past and present 
and between the Bangladesh and the UK. The structures of their comics amply illustrate the fragmentary nature of memories.

\section{Identities associated with Bangladesh}

Despite living far from their families and having very limited opportunities to visit, the women felt a very strong connection to parents, siblings and even extended family members such as nieces and nephews in Bangladesh. Their identity as Bangladeshi appeared to offer a sense of certainty and reassurance. This is perhaps best exemplified by Siddika's comic. The opening pages show a sequence of her family members: people she misses, alongside photographs of these individuals (digially altered so individuals are less recognisable). She also used several montages composed from photos she carries with her on her phone. The theme continues to the final page where she imagines her ideal future when her family is reunited.

Shahida also included some photographs of family members, but in addition she created drawings. These are accompanied by typed captions in English, but several of the pages also include handwritten Bangla. In this case, closeness to family in Bangladesh is expressed through her choice of language: Bangla is associated with Bangladesh and her family (Figure 1).

\section{[Figure 1 here]}

Even though they may have experienced upsetting events in Bangladesh, such as the death of a parent, the women's memories of growing up there were overwhelmingly positive. They felt their lives in Bangladesh had been much less stressful than their current lives in the UK. Many of the women chose brightly coloured pages when writing about their lives before coming to the UK. For example, Fatima filled a page with bright blue sky and wrote how she 'was so happy in my home country like the bright blue sky'. In contrast, one of the images she chose to depict her life in the UK also shows a blue sky, but this sky is seen through a wire fence in the foreground: the sky beyond is somewhere that is impossible to reach and inhabit.

\section{Questioning of identity}

Navigating bureaucracy, for example procedures to acquire citizenship or requirements to register for educational courses, was a frequent challenge portrayed in the comics. Identity becomes something that has to be proved and demonstrated rather than something that is certain and can be taken for granted. Shapla described the immigration problems she faced over five years and Fatima 
regretted not being able to continue her education because she could not afford to pay international fees.

However, for many of the women, the biggest change to their identity on moving to the UK was from daughter to daughter-in-law. As new wives, the women were expected to live with their inlaws, at least when they first arrived. While some women had supportive relationships with their inlaws, many experienced challenges, not only in moving to a new country, but also joining a new household. The complex relationships within extended families can place considerable pressure on the women as daughters-in-law. Sadisa, for example, wrote 'It was very hard at the beginnning to adjust to living with my in-laws'. During the course of the project, she became a full-time carer for her mother-in-law which limited the number of sessions she was able to participate in and she described this experience in her comic.

Societal and cultural expectations and responsibilities placed on women were a common theme across a number of the comics, for example, caring for elderly relatives or being expected to get married rather than completing their studies. For many of the women, getting married not only marked a transition from daughter to wife and daughter-in-law, but it also marked the end of their education. For example, Samia writes, 'So when I was 19, I got married and stopped my education. I was very sad to leave my family. I was also upset not to complete my education'.

Several of the women had experienced miscarriages and other fertility problems. On a page with a dark grey background, Shapla wrote about experiencing three miscarriages and her subsequent problems with depression. Fatima had also experienced miscarriages and included this experience in her comic. While her writing is quite restrained: 'I was so upset', a huge pram completely fills the page indicating the impact of this experience was greater than that expressed through the words alone (Figure 2). The comics format appeared to allow the women opportunities to portray issues that were difficult to discuss. They did not have a say or write a great deal, but could express the impact of such events in other ways such as through the images and colours they chose to use.

\section{[Figure 2 here]}

Language was another important aspect of identity. Although the women had learnt some English at school in Bangladesh, this was very different from the English they were likely to hear in their everyday lives in the UK and most lacked confidence in their ability to communicate in English. As a number said in their comics, they were keen to improve their English, but it was not always easy to find time and opportunities to study. Although they were offered the options of writing in Bangla or Urdu in the project, all the women were keen to produce a comic in English so their stories could be 
more widely read. Seeing their comics printed with text in English was a significant achievement for many.

\section{Finding a new identity}

The women were keen to preserve their Bangladeshi identity, which they were proud of, but they also wanted to establish a new identify for themselves that would allow them to make the most of their lives in the UK. All the women were keen to secure greater independence, for example, by learning to drive, or finding a job and earning their own income. Their ambitions were things that would have been possible, and which they would have expected to form part of their identity, had they stayed in Bangladesh. However, these were much more challenging to achieve as an immigrant. Finding ways to gain independence in a country that is still unfamiliar to them in many ways could be challenging. For example, Samia wrote: 'I can't drive yet, but I want to learn in the future. I want to become independent. I want to feel confident and be able to do things myself'.

Many of the women had studied in Bangladesh prior to getting married. Whilst some were making use of their education, for example by teaching Arabic, others felt they were not yet using their skills and knowledge fully in the UK. Most were keen to gain qualifications so that their skills would be recognised in the UK, but with family responsibilities and language difficulties, this was challenging. Juie, for instance, wrote of wanting to improve her English and IT skills, but not being able to complete the ESOL course she enrolled for because of other pressures.

Leaving their family in Bangladesh meant the women often lacked the support network they might otherwise have been able to rely on to help them to learn and develop. As well as providing practical support, families are important sources of encouragement and reassurance. Living in the UK, the women needed to seek out alternatives such as local community groups. Within their comics, several of the women mentioned participating in the Graphic Lives project as well as meeting people and getting support at [name of charity] as important steps in their journey towards creating a fulfilling life for themselves in the UK.

Having children often helped the women to feel more positive about living in the UK; although they still missed their family in Bangladesh, they were keen to ensure the best future for their children. Amina chose an image of three stars to represent her three children; they were the fixed points in her world. In Samia's comic, having children marked a turning point: her focus changes from sadness at missing her family and friends to ways she is trying to improve her life, for example, learning English, learning to drive and making more friends. 
The creational of 'fictional realities' (Salen and Zimmerman, 2004) through comics can encourage the suspension of disbelief and supports the development of counter-narratives. In this project we used this idea to encourage the women to think about the future at the end of their comic. At first, this was difficult for some, but through the medium of comics, they were given permission to imagine possibilities for what their lives might look like in the future, such as getting a job or being reunited with family (Figure 3, Siddika's comic).

[Figure 3 here]

\section{Conclusions}

The examples presented here suggest that female migrant writing has the potential to play an important role in widening our understanding of migration. As Paul White argues, 'the writing of women migrants often challenges the hegemony of views on gender roles in immigration derived largely from male-dominated research' $(1995,11)$. Moreover, telling women's migration stories through comics allows for differ themes to emerge than might be the case in more traditional formats, as well as allowing women access to alternative ways of representing their experiences and the choice of a variety of textual and pictorial languages that do not depend upon their abilities in written English.

As Eva Karpinski writes, 'writing as an immigrant woman in the genre of autobiography means writing both in a borrowed tongue and in a borrowed genre' $(2012,2)$. However, it may be that the hybrid word-image format of the autobiographical comic can be a way for migrant women to find a tongue and a genre that is not merely on loan to them, but which they can possess as their own. The women were able to choose whether to use stock photos, or draw, or use their own photographs and to include text in different languages as they wished. This was the women's first experience of a project of this type and they were far from experienced comics creators. Nevertheless, their outputs suggest that comics may indeed be a suitable 'vehicle' for 'the task of feminist rewriting and remaking of the 'mastercode' of autobiography' (Karpinski 2012, 2).

Overall, taking part in the Graphic Lives project was a positive experience for the women involved. As one said in the end of project reflections:

I've enjoyed telling my story. It's helped me to remember my background and given me an opportunity to talk about the past.

However, reflecting on the past was not always an easy experience as these comments from two of the women show: 
It was difficult emotionally to think about the past

It was hard [to think about the past]; we cried sometimes.

In the comics created, there was a common focus on everyday, seemingly insignificant, events in the lives of migrant women. Two key themes emerge from the exploration of the way women's migration experiences are depicted in these comics, namely, a focus on belonging and fluidity of identity. Migrating from Bangladesh to the UK disrupted the women's stable, established notion of their identity, which had provided certainty and coherence to their early lives. Through creating a comic depicting their life stories, the women were able to explore ideas of a 'discontinuous identity' (Pavlenko 2001) or 'variable identity' (Chowaniec 2015) demonstrating how identity can change depending on place, culture and language. Although software constraints meant we were not able to explore certain features of comics such as frames and gutters to the extent we had originally hoped, the women's comics were effective in demonstrating how comics can disrupt notions of time and space, and how the co-presence of images and words (in different languages) can help to explore different aspects of identity.

Attempting to gain a sense of belonging in a new country was of central importance to each of the protagonists in the comics created. However, for the women in these comics, this sense of belonging was not something to be gained primarily through the workplace as it might typically be in male migration stories. Instead, it was more likely to be achieved through family and community connections. The women's narratives highlight the complexity of the migrant experience: the desire to fit in on the one hand, but also the wish to express pride in their roots and to maintain a connection to their birth country. Their stories demonstrate that, for migrant women, integration is far from a straightforward process. Women typically face greater pressures to conform to socially acceptable behaviours, for example, in the ways in which they dress and this can produce stereotypes that can prevent women being seen as individuals when they move to another culture. This is an issue we aimed to address through this project, by supporting each of the women in telling her own unique, individual story that shows her personality and individual dreams and ambitions.

\section{References}

Adams, T.D. (2000) 'Heightened By Life' Vs. 'Paralyzed By Fact': Photography and Autobiography in Norma Cantú's Canícula, Biography 24(1): 57-71. 
Beaty, B. 2011. 'In Focus Comics Studies. Fifty years after film studies. Introduction.' Cinema Journal 50(3): 106-10.

Bechdel, A. (2006) Fun Home, London: Jonathan Cape

Brenner, R. (2006) ‘Graphic Novels 101: FAQ’. Horn Book Magazine, 82(2): 123-125.

Chaney, M.A. (2011) Introduction, in M.A. Chaney (Ed.) Graphic Subjects: critical essays on autobiography and graphic novels, Madison: The University of Wisconsin Press.

Chowaniec, U. (2015) The gendering of migration: women's writing, displacement and melancholy, lecture's notes [sic], http://www.sant.ox.ac.uk/sites/default/files/relateddocuments/lecture_notes_2015_february_.pdf (accessed 3 March 2016).

Chute, H. (2011). 'Comics Form and Narrative Lives'. Profession 2011: 107-117.

Chute, H. (2010) Graphic Women: Life narrative and contemporary comics, New York: Columbia University Press.

Chute, H. (2008) Comics as Literature? Reading graphic narrative, Publications of the Modern Language Association of America (PMLA) 123(2): 452-65.

Courtman, S. (2012) Women writers and the Windrush generation: a contextual reading of Beryl Gilroy's In Praise of Love and Children and Andrea Levy's Small Island, EnterText, 'Special Issue on Andrea Levy,' 9 (2012): 84-104, https://www.brunel.ac.uk/_data/assets/pdf_file/0006/198060/7_Courtman_Women-Writers-andthe-Windrush-Generation_FINAL.pdf (accessed 3 March 2016).

Davis, R.G. (2005). A graphic self: comics as autobiography in Marjane Satrapi's Persepolis, Prose Studies: History, Theory, Criticism, 27(3): 264-79.

Davis-McElligatt, J. (2010).Confronting the interactions of race, immigration and representation in Chris Ware's comics, in D.M. Ball \& M.B. Kuhlman (Eds.) The Comics of Chris Ware: drawing is a way of thinking, Jackson MS: University Press of Mississippi.

El Refaie, E. (2010) Subjective Time in David B's Graphic Memoir 'Epileptic', Studies in Comics 1(2): 281-299. 
El Refaie, E. (2008). Autobiographical Comics: life writing in pictures, Jackson, MS: University Press of Mississippi.

Gameiro, S, et al (forthcoming)

Groensteen, T. (2007) The System of Comics, Jackson: University Press of Mississippi.

Iser, W. (1989) Prospecting: From Reader Response to Literary Anthropology, Baltimore: John Hopkins University Press.

Jenkins, J. (2006) World Englishes, London: Routledge.

Karpinski, E.C. (2015) Borrowed Tongues: life writing, migration, and translation, Waterloo, ON:

Wilfrid Laurier University Press.

Masschelein, A. (2008) Foreword, Image and Narrative: online magazine of the visual narrative 22, http://www.imageandnarrative.be/inarchive/autofiction2/masschelein.html (accessed 3 March 2016).

McCloud, S. (1994) Understanding Comics: the invisible art. New York: Harper Collins.

Pavlenko, A. (2001) Language learning memoirs as a gendered genre, Applied Linguistics 22(2):21340.

Rushdie, S. (1982) Imaginary Homelands, London Review of Books 4(18): 18-19,

http://www.Irb.co.uk/v04/n18/salman-rushdie/imaginary-homelands (accessed 3 March 2016).

Salen, K. and Zimmerman, E. (2004) Rules of Play: game design fundamentals (Cambridge, MA, MIT Press).

Speigelman, A. (2003) The Complete MAUS, London: Penguin.

Tan, S. (2007) The Arrival, London: Hodder Children's Books

Thompson, C.R. (2003) Blankets, Marietta, Ga: Top Shelf Productions.

Ulanowicz, A. (2011). Review of 'Graphic Women: Life narrative and contemporary comics', ImageText 5(4), http://www.english.ufl.edu/imagetext/archives/v5 4/ulanowicz/ (accessed 3 March 2016). 
Ware, C. (2001) Jimmy Corrigan: the smartest kid on earth, London: Jonathan Cape.

White, P. (1995) Geography, Literature and Migration, in Connell, J, King, R. and White, P. (eds) (1995), Writing Across Worlds: Literature and Migration, London: Routledge.

Yang, G.L. (2007) Stranger in a Strange Land, The New York Times, http://www.nytimes.com/2007/11/11/books/review/Yang-t.html?_r=0 (accessed 3 March 2016).

' http://laydeezdocomics.wordpress.com/

in http://grassrootscomics.net/

iii https://bookcreator.com/ 